\title{
KAMPANYE SOSIAL BAHAYA BULLYING DALAM PERGAULAN REMAJA
}

\author{
Ayu Soraya, Yoza Rizaldi \\ Program Studi Desain Komunikasi Visual Fakultas Seni dan Desain \\ Universitas Potensi Utama \\ awlya.ayu@gmail.com, rizaldithunder@gmail.com
}

\begin{abstract}
ABSTRAK
Bullying merupakan tindakan penyalahgunaan kekuasaan oleh seseorang atau sekelompok orang dilakukan oleh anak-anak remaja dimana perilaku bullying berdampak pada psikologis korban. Rancangan kampanye sosial ditujukan kepada remaja dan anak-anak berjenis kelamin laki-laki dan perempuan yang berada di kota medan. Perancangan Kampanye Sosial digunakan yaitu $5 \mathrm{~W}+1 \mathrm{H}$ dan pengambilan data dengan menggunakan kuesioner. Hasil rancangan kampanye sosial berupa media utama berupa poster dan media pendukung berupa pin dan stiker. Kampanye sosial ini akan di implementasikan di sekolahsekolah agar tepat sasaran.
\end{abstract}

Kata Kunci: Bullying, Kampanye Sosial, Remaja

\begin{abstract}
Bullying is an act of abuse of power by a person or group of people carried out by adolescent children where bullying behavior affects the psychological victim. The design of a social campaign is aimed at boys and girls in the city of Medan. The Social Campaign design is used, namely $5 \mathrm{~W}+1 \mathrm{H}$ and data collection using a questionnaire. The results of the social campaign design are in the form of the main media in the form of posters and supporting media in the form of pins and stickers. This social campaign will be implemented in schools to be right on target.
\end{abstract}

Keywords: Bullying, Social Campaigns, Youth

\section{PENDAHULUAN}

Bullying atau juga dikenal sebagai Penindasan sudah sangat sering terjadi bahkan dapat dijumpai disetiap sudut daerah tempat tinggal. Banyak remaja mengindikasikan bullying atau penindasan sebagai bahan candaan semata agar suasana pertemanan tidak monoton.

Riauskina, dkk (2005) mendefinisikan school bullying sebagai perilaku agresif yang dilakukan berulang-ulang oleh seorang atau sekelompok siswa yang memiliki kekuasaan tehadap siswa/siswi yang lebih lemah dengan tujuan menyatiki orang tersebut.

Proses bullying atau penindasan tidak hanya terjadi secara langsung, bullying atau penindasan juga dapat terjadi pada dunia maya seperti social media atau juga grup diskusi. Korban bullying atau penindasan bisa siapa saja, dari kalangan anak kecil, remaja, hingga orang dewasa. 
Dampak yang dihasilkan pada korban bullying atau penindasan bisa merupakan hal yang positif ataupun sebaliknya. Namun dampak yang lebih dominan merupakan hal yang negative, dikarenakan banyaknya korban bullying atau penindasan yang takut untuk melihat dunia luar .

Faktanya kasus bullying disekolah mengalami peningkatan dari 79 kasus pada awal tahun 2016 menjadi 113 kasus pada tahun akhir tahun 2016. Ketua Komisi Perlindungan Anak Indonesia (KPAI) Asrorun Ni'ram Sholeh mengatakan " naiknya jumlah anak sebagai pelaku kekerasan di sekolah menunjukkan adanya faktor lingkungan yang tidak kondusif bagi perlindungan anak. Faktor keteladanan yang kurang serta internalisasi semangat tanggung jawab dan kewajiban anak belum optimal " (sumber: https://www.republika.co.id).

Beberapa fakta terbaru memunculkan dua tempat pendidikan tingkat tinggi, yakni: Universitas Gunadharma dan Sekolah Tinggi Ilmu Pelayaran. Beberapa pelajar terlibat dalam aksi bullying dan para pelaku mendapatkan sanksi tegas dari kedua tempat pendidikan tersebut. Banyaknya kasus pembullyan pada lingkungan kehidupan seharihari seperti Seorang pelajar SMK menjadi pesuruh suatu kelompok pelajar di lingkungan sekolah maupun di luar lingkungan sekolah agar dapat menjadi anggota kelompok tersebut, satu kelompok pelajar yang melakukan tidakan pembullyan kepada hanya satu orang sehingga pelajar tersebut takut kepada orang lain, pembullyan yang bermula hanya dari candaan kecil yang berkelanjutan hingga memberikan perasaan tidak nyaman terhadap korban.

Metode yang digunakan dalam penelitian ini menggunakan metode $5 \mathrm{~W}+1 \mathrm{H}$ untuk melakukan pemecahan masalah. Adapun analisis data menggunakan metode $5 \mathrm{~W}+$ $1 \mathrm{H}$ sebagai berikut :

What : Apa tema yang digunakan pada Kampanye Sosial ini ?

Kampanye Sosial ini menggunakan tem " Bahaya Pembullyan Dalam Pergaulan Remaja ".

Where : Dimana target lokasi Kampanye Sosial ini ?

Difokuskan kepada seluruh remaja di Indonesia.

When : Kapan Kampanye Sosial ini diterapkan?

Masa sekarang, diharapkan diapresiasi oleh seluruh masyarakat Indonesia untuk perubahan yang lebih baik.

Why : Kenapa membuat Kampanye Sosial dengan tema " Bahaya Pembullyan Dalam Pergaulan Remaja " ?

Karena Maraknya kasus aksi bullying di Indonesia dalam 2 tahun terakhir.

Who : Kepada siapa Kampanye Sosial ini ditargetkan?

Seluruh masyarakat Indonesia.

How : Bagaimana cara penyampaian Kampanye Sosial ini ?

Melalui Poster Kampanye Sosial " Stop Bullying ".

\section{STUDI LITERATUR}

Penelitian yang menjadi rujukan adalah Perancangan Komunikasi Visual Kampanye Sosial Stop Bullying untuk Anak-Anak Sekolah Dasar (SD) di Wilayah Sragen karya Vitria Narwastu yang mengangkat kasus pembulyan dikalangan anakanak sekolah dasar dengan konsep kreatif menampilkan ilustrasi dalam bentuk kartun anak-anak dengan typografi yang disesuaikan target audience sehingga menarik dan mudah dipahami oleh anak-anak Sekolah Dasar (SD). 
Rujukan penelitian selanjutnya adalah Kampanye Pencegahan Bullying di Lingkungan Sekolah oleh Muhamad Hanafi Zulfani dan Drs. Indarsjah Tirtawidjaja (2014). Tujuan dalam penelitian ini adalah merancang kampanye sosial dilingkungan sekolah yang bertema "Be a Real Friend" dengan stategi kreatif fun dan evokatif agar mampu mencegah tindak bullying dilingkungan sekolah.

\section{PEMBAHASAN}

\section{KONSEP DESAIN}

Konsep perancangan Iklan Layanan Masyarakat ini meliputi tahap penentuan target audience yaitu demografis, geografis, psikografis dan behavioral.

1. Demografis

Adapun ruang lingkup masyarakat yang ditargetkan adalah

Anak-anak umur $\leq 15$ Tahun

Remaja umur 16-20 Tahun

Dewasa umur 21-30 Tahun

Adapun jenis kelamin untuk ruang lingkup masyarakat adalah semua jenis kelamin, yaitu : Pria dan Wanita

2. Geografis

Adapun letak geografis ruang lingkup Kampanye Sosial, yaitu : Seluruh kawasan Indonesia.

3. Psikografis

Adapun Kelas sosial yang ditujukan Kampanye Sosial ini adalah semua kalangan masyarakat yang memiliki potensi untuk melakukan aksi bullying dan pencegahan aksi bullying.

4. Behavioral

Adapun Kampanye Sosial ini ditujukan untuk masyarakat yang belum paham dampak yang diakibatkan dari aksi bullying.

\section{ANALISIS OBJEK}

1. Kuesioner

Menurut Sugiyono (2010:199) Kuesioner adalah suatu teknik pengumpulan data dengan memberikan beberapa pertanyaan ataupun pernyataan secara tertulis pada responden agar menjawab pertanyaan tersebut.

Kampanye Sosial ini menggunakan Metode Kuesioner untuk analisis objek. Pertanyaan untuk Kuesioner ini sebagai berikut : 


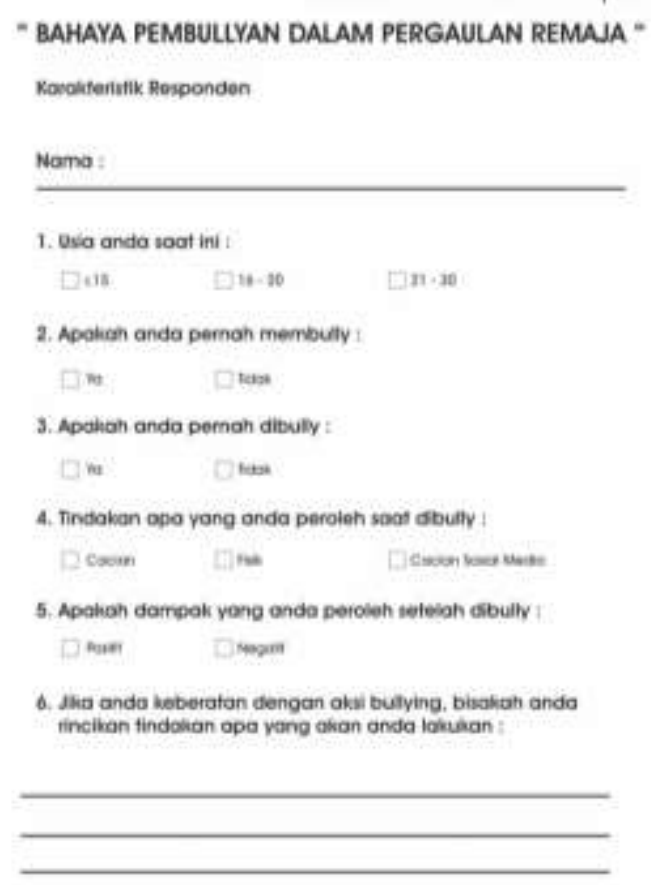

Gambar 1. Kuesioner Kampanye Sosial " Bahaya Pembullyan Dalam Pergaulan Remaja " (Sumber: Yoza, 2016)

Adapun 10 responden yang mewakili persentase analisis terhadap objek ini sebagai berikut :

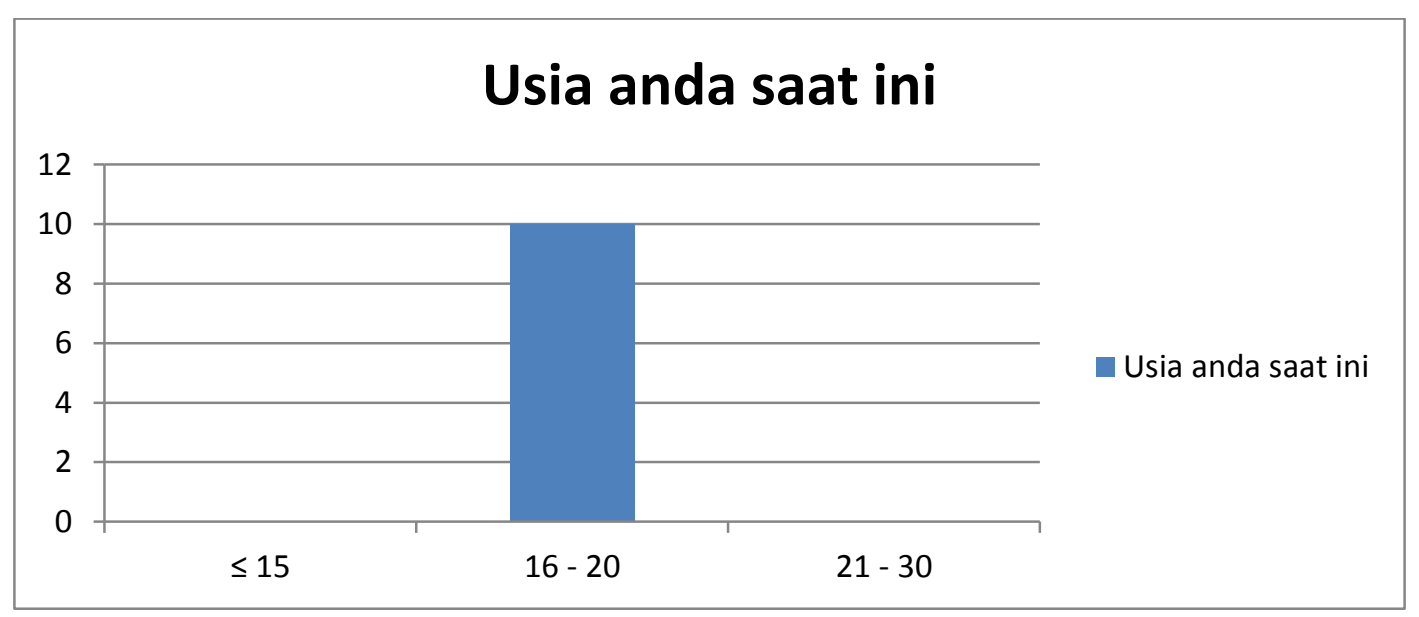

Gambar 2. Pertanyaan Responden "Usia"

(Sumber: Yoza, 2016) 


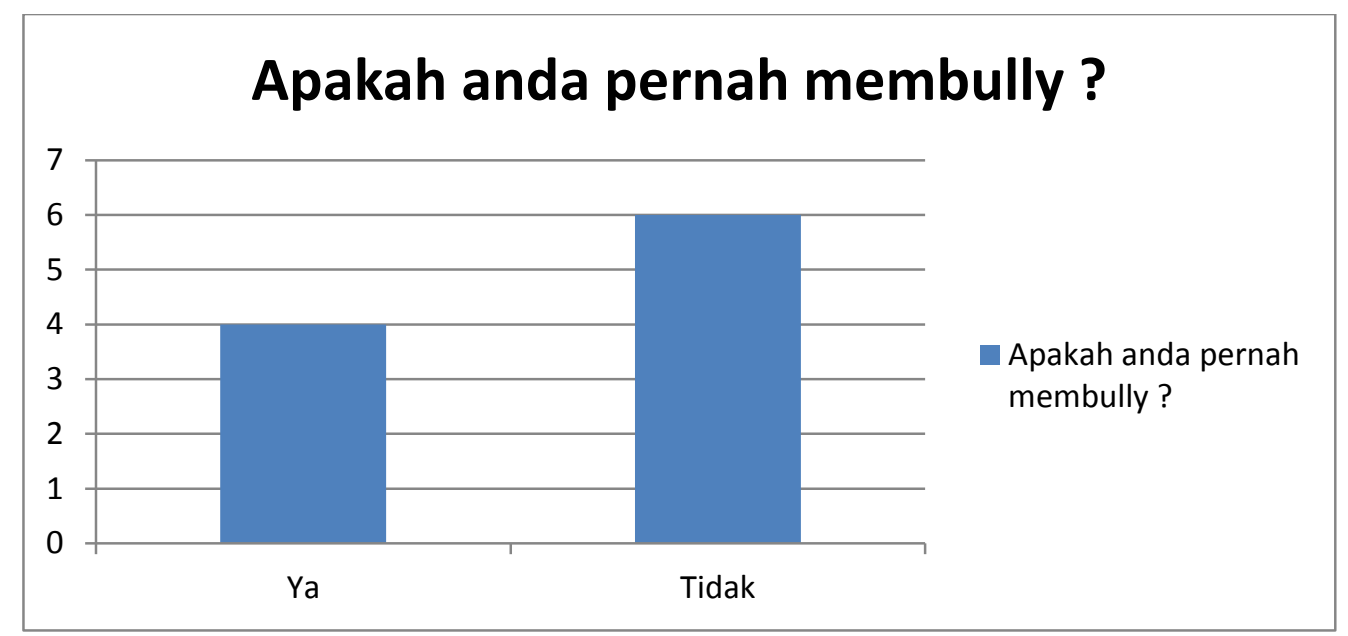

Gambar 3. Pertanyaan Responden "Pernah Membuli" (Sumber: Yoza, 2016)

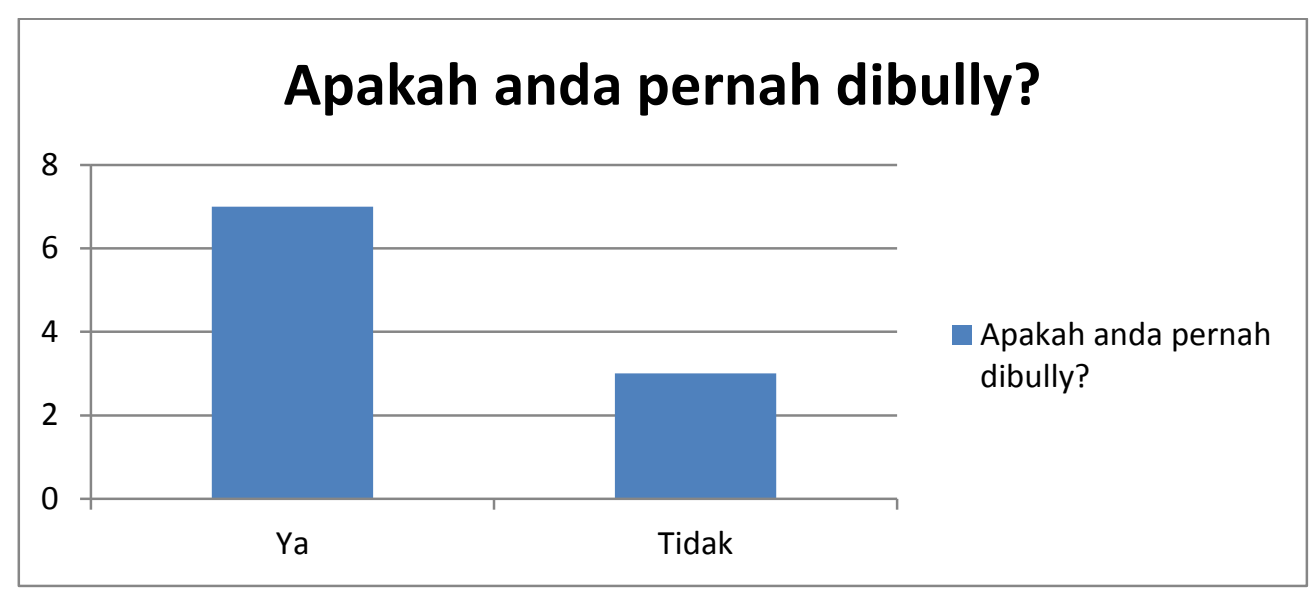

Gambar 4. Pertanyaan Responden "Pernah Dibuli" (Sumber: Yoza, 2016)

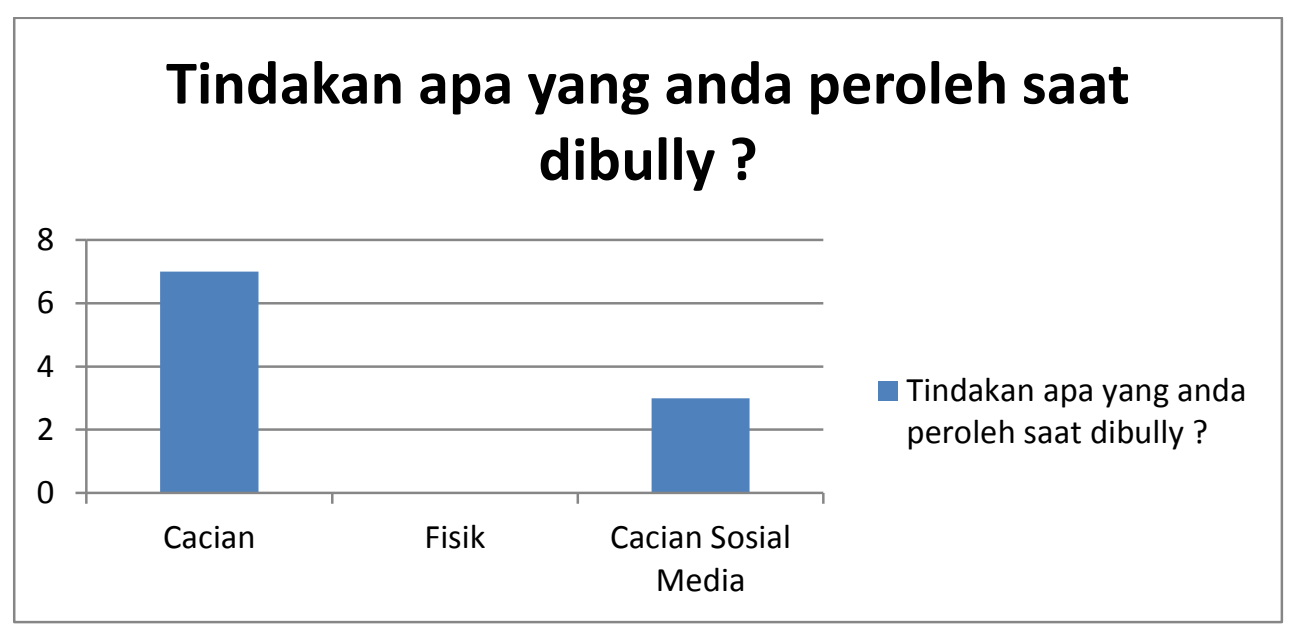

Gambar 5. Pertanyaan Responden "Manfaat Membuly" (Sumber: Yoza, 2016) 


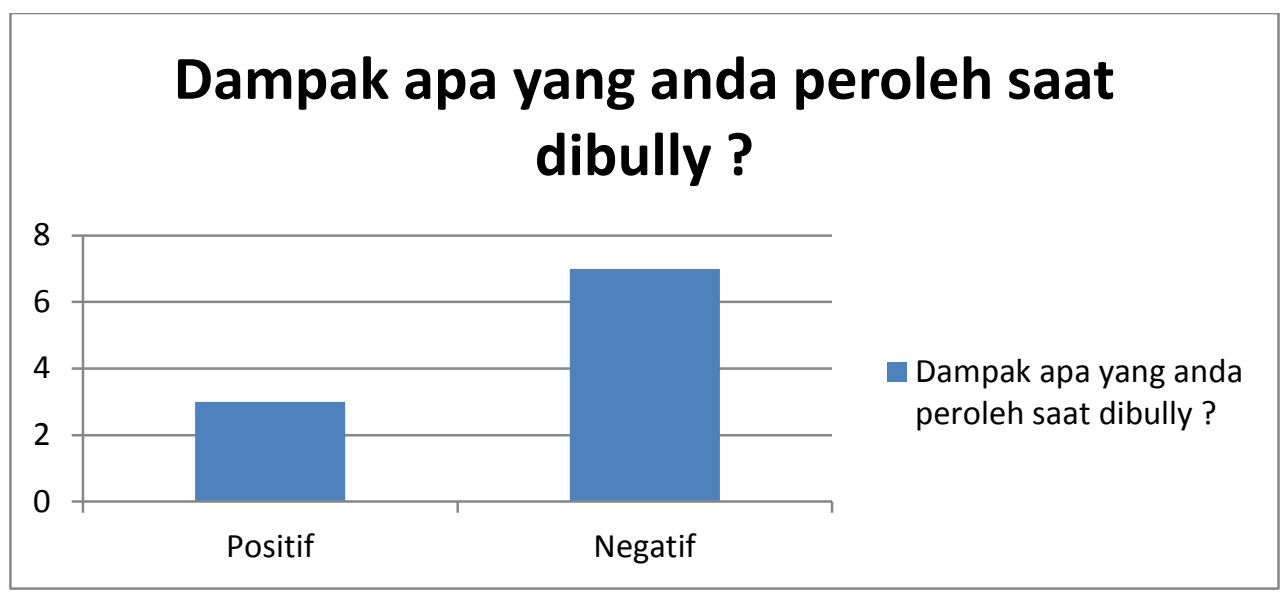

Gambar 6. Pertanyaan Responden "Dampak Dibully"

(Sumber: Yoza, 2016)

Kesimpulan persentase kuesioner memberikan hasil : rata-rata remaja berumur 16 hingga 20 tahun dominan tidak pernah melakukan aksi bullying, tetapi dominan dibully dengan tindakan cacian secara langsung yang memberikan efek negatif pada remaja tersebut.

\section{STRATEGI KREATIF}

Pesan adalah informasi yang disampaikan dalam bentuk tertulis ataupun lisanmelalui media perantara. Rancangan Kampanye Sosial dibuat semenarik mungkin. Rancangan akan dibuat simple dan mengangkat efek warna yang indah. Visualisasi akan dirancang dengan baik dengan berbagai makna yang akan disampaikan tetapi tidak menghilangkan tujuan dari Kampanye Sosial.

Adapun bentuk pesan yang akan disampaikan adalah :

\section{Verbal}

Pesan verbal adalah Pesan yang disampaikan secara lisan berupa kata-kata, dan dimengerti oleh penerimanya berdasarkan pendengaran .

\section{Non Verbal}

Pesan non-verbal adalah penyampaian pesan tidak langsung menggunakan katakata langsung tetapi menggunakan bahasa tubuh, tingkah laku gerak gerik dan mimik wajah pengirim pesan.

\section{STRATEGI MEDIA}

\section{Media Utama}

Media Utama yang dipilih untuk Kampanye Sosial " Bahaya Pembullyan Dalam Pergaulan Remaja " adalah poster. Poster merupakan media yang baik dan mudah untuk di rancang.

Walaupun demikian, makna yang dicantumkan dalam poster merupakan yang baik karena ukuran yang luas dan peletakan di jalan merupakan sesuatu yang ideal untuk Kampanye Sosial.Poster adalah media yang sangat baik karena mendukung visualisasi 
yang lebih luas dan peletakan kata-kata yang kreatif.Hasil jadi Poster diaplikasikan di berbagai media. Untuk ukuran Poster memuat ukuran 80 x $60 \mathrm{~cm}$. Media untuk remaja dan anak-anak poster di temple di sekitar lingkungan Sekolah Mereka, dikarenakan lebih mudah tampak oleh mata. Media untuk dewasa keatas poster dibagikan di jejaring sosial, dikarenakan penggunaan jejaring sosial lebih tinggi oleh orang dewasa keatas.

\section{Media Pendukung}

- Pin

Hasil jadi diaplikasikan dengan membaginya di persimpangan jalan, lembaga edukasi, dll. Ukuran pin $58 \mathrm{~mm}$, diameter lingkaran dalam pin $58 \mathrm{~mm}$ dan diameter lingkaran luar pin $70 \mathrm{~mm}$.

- Stiker

Hasil juga diaplikasikan dengan membaginya di persimpangan jalan, lembaga edukasi, dll.Ukuran stiker adalah 8 x $6 \mathrm{~cm}$, dengan posisi landscape.

\section{KONSEP KREATIF}

Konsep perancangan ini menggunakan 5 tagline yang akan di aplikasikan pada kampanye sosial :

\section{Word Like a Weapon, They Can Kill}

Berfokus kepada senjata, perkataan layaknya senjata. Efek yang dihasilkan juga dapat membuat seseorang terbunuh karena aksi bullying tersebut.

\section{1 Word 4 Hurts}

Hanya satu kata yang keluar dari mulut dalam membuat empat organ pada tubuh tersakiti layaknya sebuah pukulan pada fisik yang diterima oleh korban aksi bullying.

\section{Power of Attack, Word Attack \& Physical Attack, Although it has a different shape The result is the same}

Kekuatan dalam arti efek yang dihasilkan dari Perkataan dan Pukulan adalah sama, namun hanya berbeda dalam bentuk fisik.

\section{Your Words Injure My Heart}

Umumnya aksi bullying, perkataan yang dihasilkan dapat melukai perasaan seseorang baik secara langsung atau tidak langsungtercapai atau tidak. Banyak yang harus dipikirkan dalam merancang sebuah tipografi untuk kampanye sosial. Perancangan kampanye ini menggunakan tipografi jenis Chiller untuk tagline dalam perancangan. Font Chiller dipilih karena menimbang tentang bentuk dari font yang mencekam, cocok untuk dijadikan tagline kampanye sosial ini.

\section{Last Choice With a Smile}

Terakhir, hanya pilihan ini yang dianggap mampu mengakhiri penderitaan korban aksi bullying dan pilihan ini di ambil dengan senyuman kebahagiaan. 


\section{KONSEP VISUAL}

\section{Warna}

Warna adalah salah satu unsur yang terpenting dalam proses pembuatan kampanye sosial. Kampanye sosial ini menerapkan warna CMYK dalam perancangannya. Warna yang digunkan dalam kampanye social ini maksimal 3 warna, warna yang digunakan sesuai dengan konsep yang sudah dijelaskan pada konsep kreatif. Ada pun Sample warna

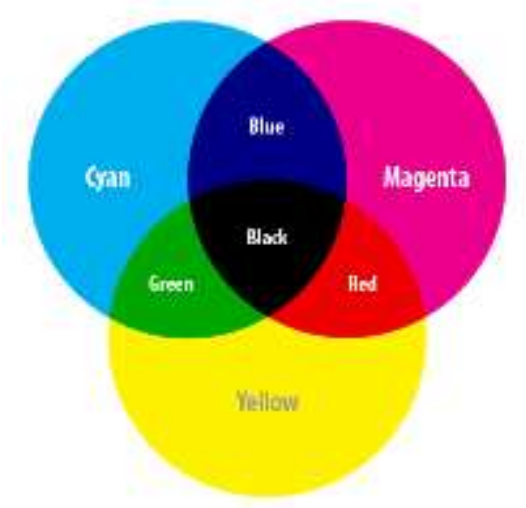

Gambar 7. Sample warna CMYK (Sumber: Yoza, 2016)

\section{Tipografi}

Tipografi merupakan komposisi utama dalam kampanye sosial. Pesan yang disampaikan dari tipografi akan sangat menentukan tujuan kampanye sosial dapat tercapai atau tidak. Banyak yang harus dipikirkan dalam merancang sebuah tipografi untuk kampanye sosial. Perancangan kampanye ini menggunakan tipografi jenis font "ChunckFive Roman “ untuk tagline dalam perancangan. Font "ChunkFive Roman" dipilih karena menimbang tentang bentuk dari font yang mencekam, cocok untuk dijadikan tagline kampanye sosial ini

\section{ChunkFive Roman}

\section{Gambar 8. Font untuk Tagline dalam Kampanye Sosial}

(Sumber: Yoza, 2016)

Adapun untuk subline tipografi yang dipakai adalah "Helvetica Family", Dikarenakan tipografi ini sangat mudah dibaca ketika ukuran font kecil 


\section{Helvetica}

Gambar 9. Font untuk Subline dalam Kampanye Sosial (Sumber: Yoza, 2016)

\section{PROSES PENCIPTAAN}

\section{Sketsa}

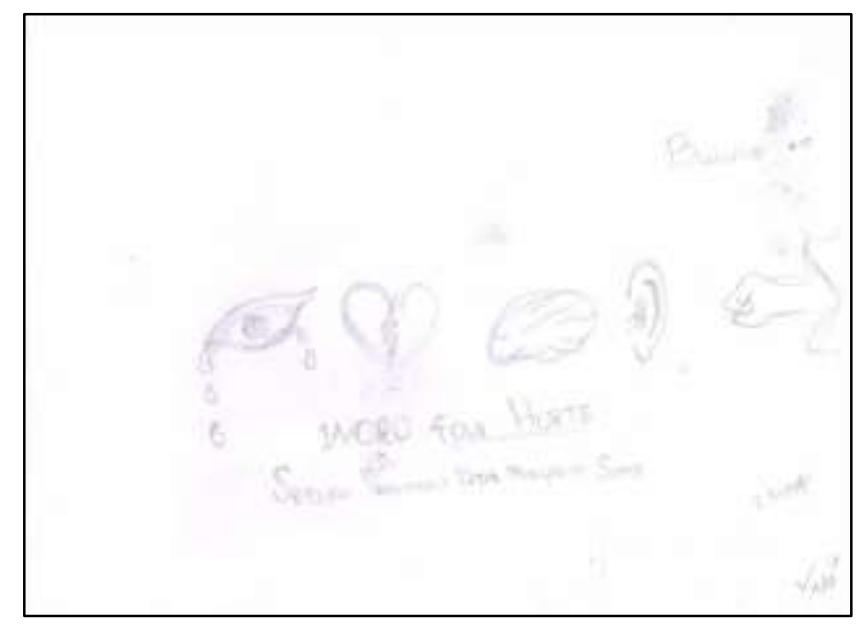

Gambar 10. Sketsa I

(Sumber: Yoza, 2016)

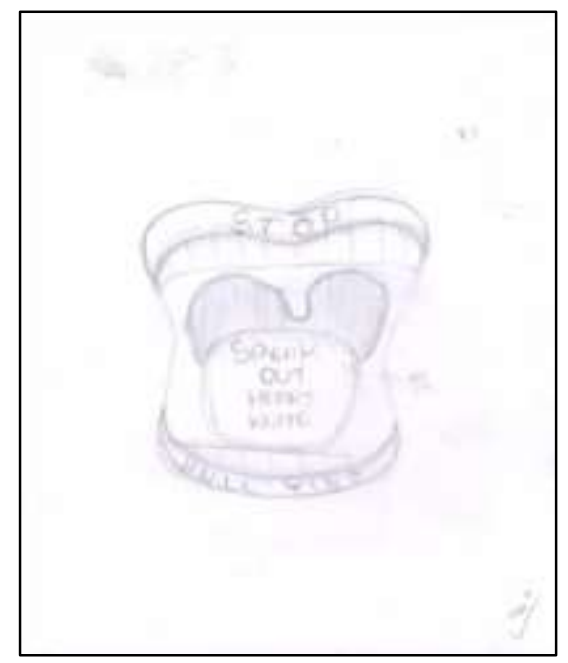

Gambar 11. Sketsa II

(Sumber: Yoza, 2016)

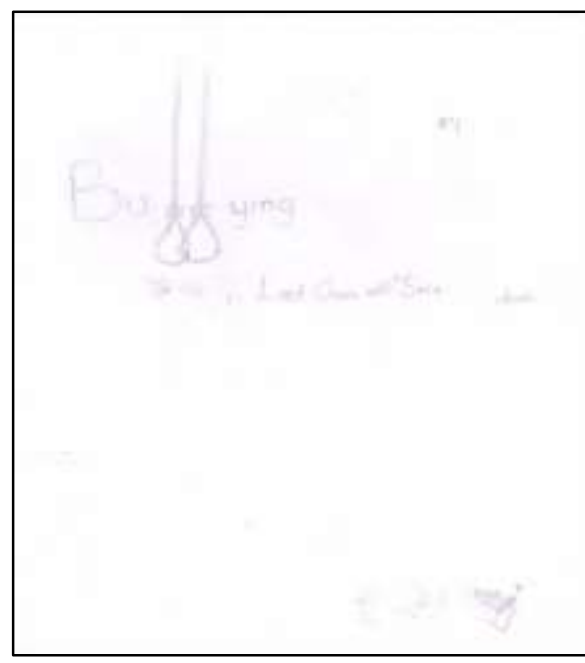

Gambar 12. Sketsa III

(Sumber: Yoza, 2016) 


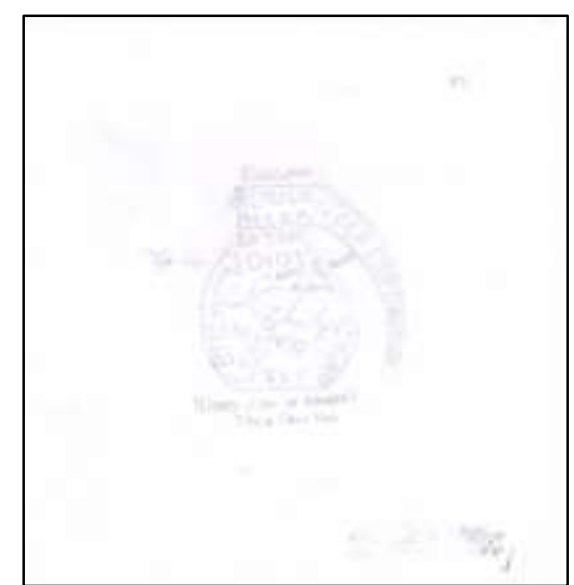

Gambar 13. Sketsa IV

(Sumber: Yoza, 2016)

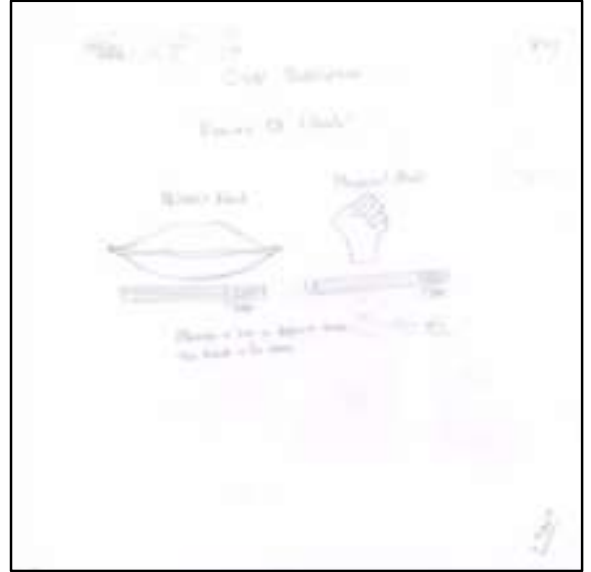

Gambar 14. Sketsa V

(Sumber: Yoza, 2016)

\section{Desain Digital}
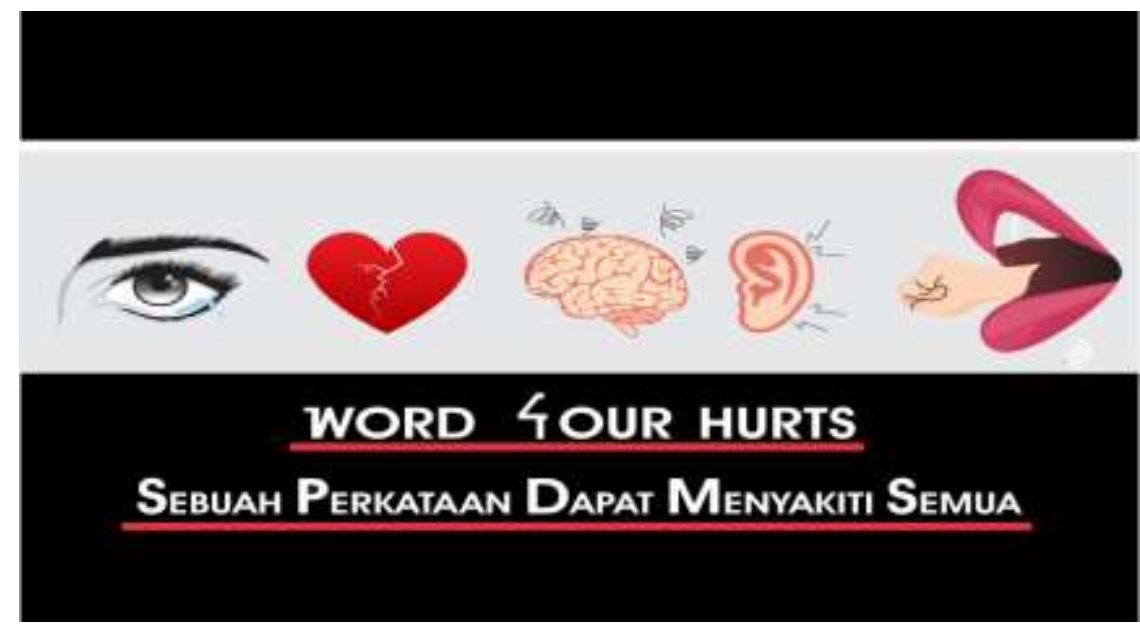

Gambar 15. Desain Digital I

(Sumber: Yoza, 2016)

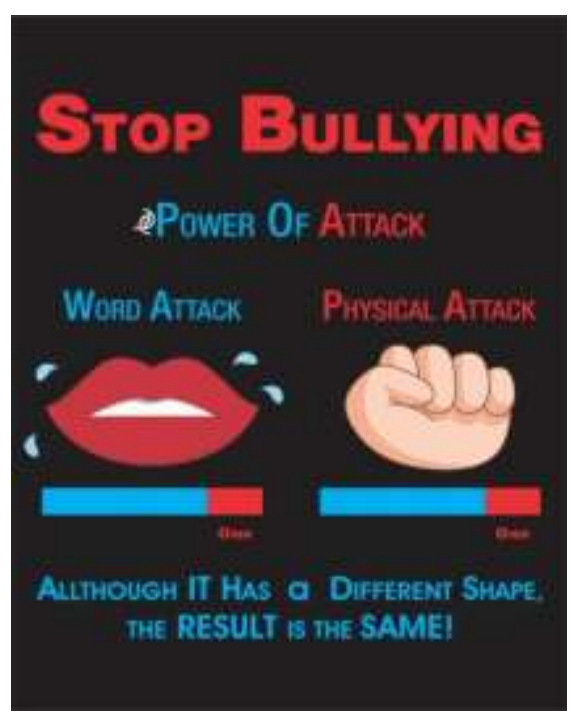

Gambar 16. Desain Digital II (Sumber: Yoza, 2016)

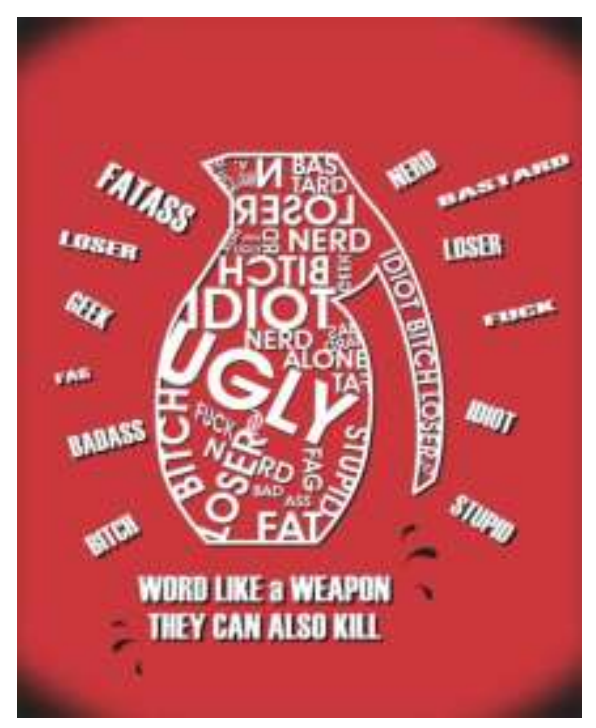

Gambar 17. Desain Digital III (Sumber: Yoza, 2016) 


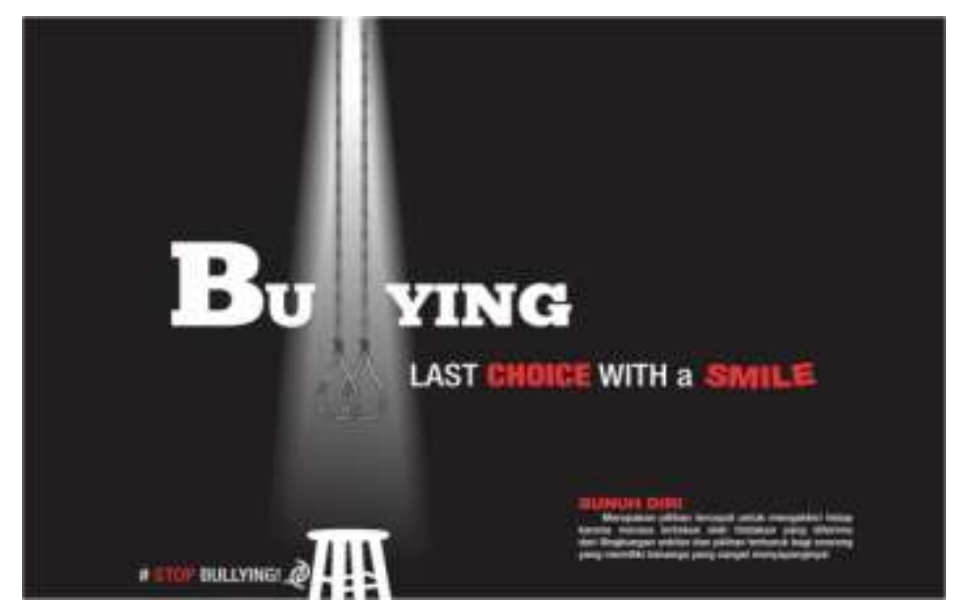

Gambar 18. Desain Digital V

(Sumber: Yoza, 2016)

\section{HASIL}

Media Utama

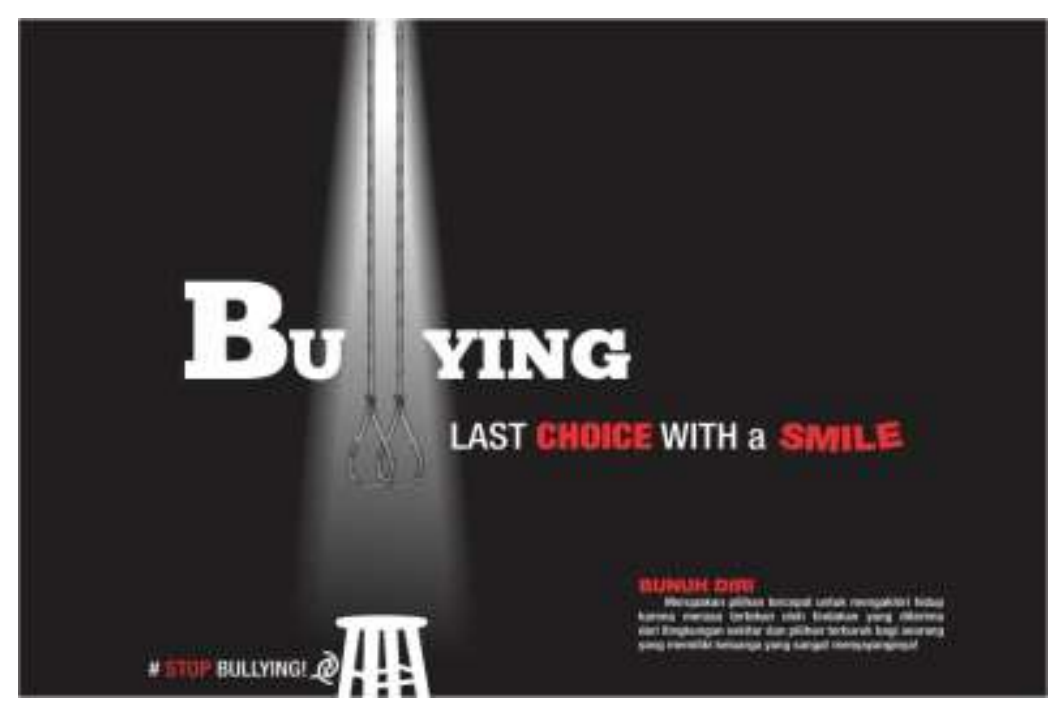

Gambar 19. Media Utama "Poster"

(Sumber: Yoza, 2016) 


\section{Media Pendukung}

- Pin

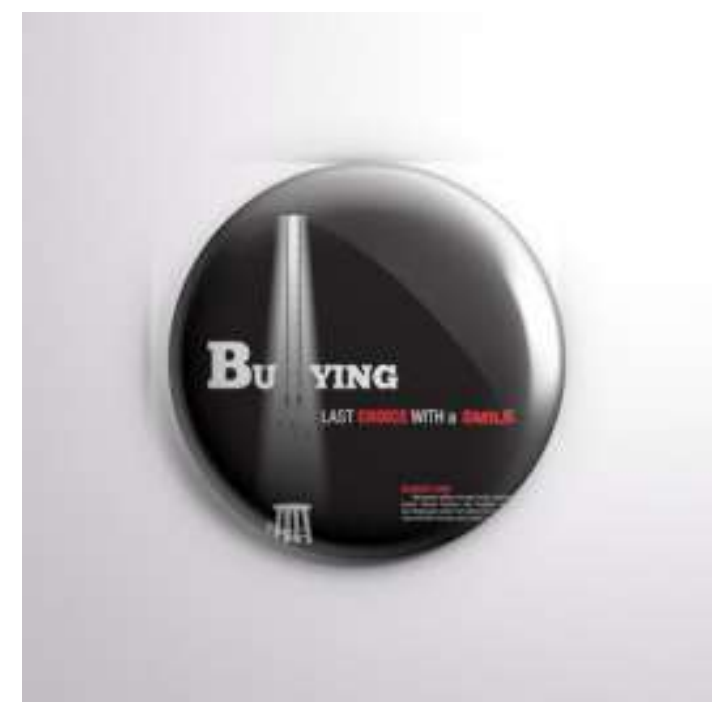

Gambar 20. Media pendukung pin

(Sumber: Yoza, 2016)

- Stiker

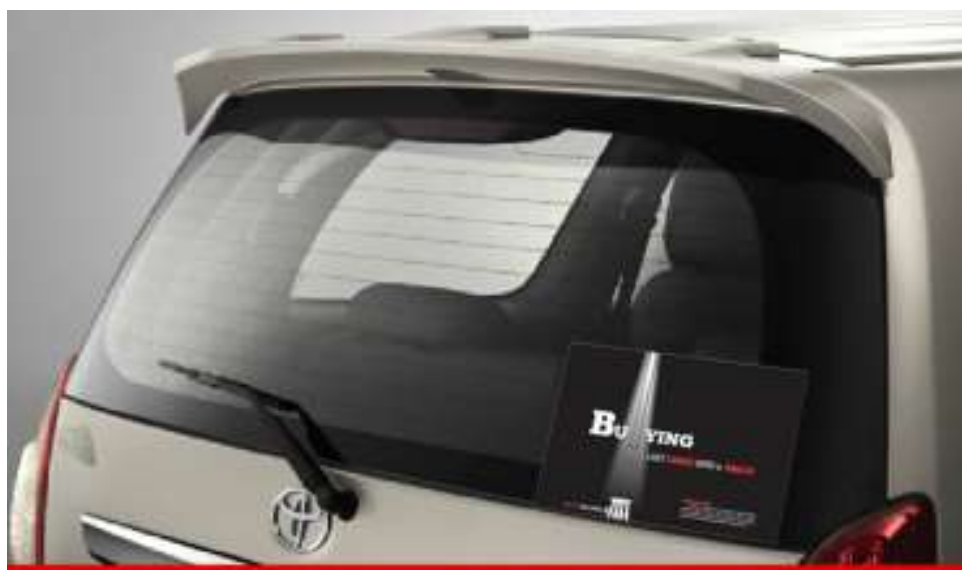

Gambar 21. Media pendukung stiker

(Sumber: Yoza, 2016)

\section{KESIMPULAN}

Dalam penelitian ini dapat disimpulkan bahwa kampanye sosial ini akan di sosialisasikan kepada masyarakat dalam bentuk media utama berupa poster dan media pendukung berupa stiker dan pin. Iklan Layanan ini memiliki target audience yaitu masyarakat umum terutama anak-anak dan remaja dengan jenis kelamin laki-laki dan perempuan. 


\section{DAFTAR PUSTAKA}

[1] Narwastu, Vitria. 2011. "Perancangan Komunikasi Visual Kampanye Sosial Stop Bullying ! Untuk Anak-anak Usia Sekolah Dasar (SD) di Wilayah Sragen." Skripsi. Fakultas Sastra dan Seni Rupa Universitas Negeri Sebelas Maret.

[2] Riauskina, I.I., Djuwita, R., dan Soesetio, S.R. (2005). "Gencet-gencetan" dimata siswa/siswi kelas 1 SMA: Naskah kognitif tentang arti, skenario, dan dampak "gencet-gencetan". Jurnal Psikologi Sosial, 12(01), 1-13

[3] Sugiyono. 2010. Metode Penelitian Pendidikan Pendekatan Kuantitatif, kualitatif, dan $R \& D$. Bandung: Alfabeta

[4] Zulfani, Muhamad Hanafi \& Indarsjah Tirtawidjaja. 2014. "Kampanye pencegahan Bullying di Lingkungan Sekolah." Jurnal tingkat Sarjana bidang Senirupa dan Desain No. 1. Program Studi Sarjana Desain Komunikasi Visual, Fakultas Seni Rupa dan Desain (FSRD) ITB.

[5] https://www.republika.co.id/berita/nasional/umum/30/12/30/o067zt280-kpai-kasusbullying, diakses tahun 2016 